\title{
Analysis of fire departments location in St. Petersburg
}

\author{
Maria Rozhina ${ }^{1}$, Arseniy Lyubomirskiy ${ }^{1}$, Liliia Talipova ${ }^{1 *}$ \\ ${ }^{1}$ Peter the Great St. Petersburg Polytechnic University, Politechnicheskaya Street, 29, Saint \\ Petersburg, 195251, Russia
}

\begin{abstract}
This article is to identify and visualize the territory of St. Petersburg, which is not included in the service area of fire departments. The article provides an analysis of standards and the calculation of the maximum distance from the fire department to the object of the alleged fire. As a result of the calculation, it cleared up that the maximum service radius of one fire department is $2.5 \mathrm{~km}$. A map was also made showing the service radii of fire stations in St. Petersburg. The authors represented zones that do not fall within the radii, and suggested possible solutions to certain problems.
\end{abstract}

\section{Introduction}

St. Petersburg is a large city that is developing rapidly, which means not only an increase in its plan dimension, but also an increase of emergencies [1-7]. The quick arrival of the fire engine ensures the preservation of property, timely liquidation of the fire, and, most importantly, the saving of human lives and minimization of damage to health. According to Article 76 of the Federal Law of July 22, 2008 N 123-FL, the arrival time of the first fire brigade to the place of call in urban areas should not exceed 10 minutes. The constantly increasing number of new residential complexes with low infrastructure in the city and its districts, numerous large traffic jams, temporary road repairs and weather conditions reduce the radii of service of fire departments, and for this reason there is a need to identify unsafe areas to which fire brigade in case of emergency will not be able to arrive within a certain time [8-12]. Three main regulatory documents, that control value of time, distance and location of fire department, make current situation more complicated. All of them impose different requirements which leads to confusion in the calculations [13-15].

Due to the mentioned problems, it is important to determine which areas of the city are not covered by fire departments to prevent possible fires [16-19].

In articles, the authors propose new design solutions to improve life safety, including multifunctional fire protection facilities. There is an analysis of the amendments to the Federal Law of July 22, 2008 No. 123-FL "Technical Regulations on Fire Safety Requirements" in articles. The authors of articles calculate the locations of fire stations, map a route, and also develop a mathematical model of determination of the maximum permissible distance from a building to a fire department. Krasavin A.V. in his article

\footnotetext{
*Corresponding author: author@email.org
} 
analyzes the possibility of fulfilling in practice the requirements of regulatory documents of fire safety. Lukyanova Yu.A. represents an analysis and comparison of domestic and foreign standards for the design of fire protection facilities. Alderov I.S. in considers the problems associated with fire safety in the residential sector and identifies its most frequent violations.

The aim of this article is to identify and visualize the territory of St. Petersburg, which is not included in the service area of fire departments. In accordance with the aim, the following goals are:

1. To analyze the regulatory documents governing fire standarts

2. Compile statistics and determine where fires occur most often

3. In accordance with regulatory documents, calculate the radius of service of one fire department

4. Construct a map of St. Petersburg with marked radii of service of fire departments

5. Determine the reasons for the lack of fire departments in St. Petersburg and propose possible solutions to the problems identified in the article.

\section{Research}

In the Federal Law "Technical Regulation on Fire Safety Requirements" dated 07.22.2008 No. 123-FL the time of arrival of a fire department for the city is 10 minutes. There is a calculation of the maximum permissible distance from the object of the alleged fire where length of the way depends on the intended purpose of the departure of the fire brigade in Set of Rules No.11.13130.2009. In Set of Rules No.42.13330.2011, the maximum service radius of one fire station is equal to $3 \mathrm{~km}$. All three regulatory documents use different units of measurement. This problem leads to the fact that in process of the calculation there is no single requirement, and the implementation of each of them is almost impossible. The lack of clarity and accuracy complicates the work of designers and experts who cannot make a single decision with confidence. These regulatory documents, each of which differently justifies the location of the fire department in the city, cause a confusion and an inability to satisfy all the requirements in full.

Despite the significant financing of the maintenance of units of the State Fire Service in St. Petersburg (3 billion rubles per year), the number of fire departments is insufficient. A preliminary analysis of the fire stations' addresses shows that departments are located irrationally from an economic point of view.

The collection and analysis of data on the fires that occurred in 2018 from the website of Ministry of the Russian Federation for Civil Defense, Emergency Management and Natural Disasters Response in St. Petersburg indicates that the largest number of them occur in residential buildings (Figure 1). 


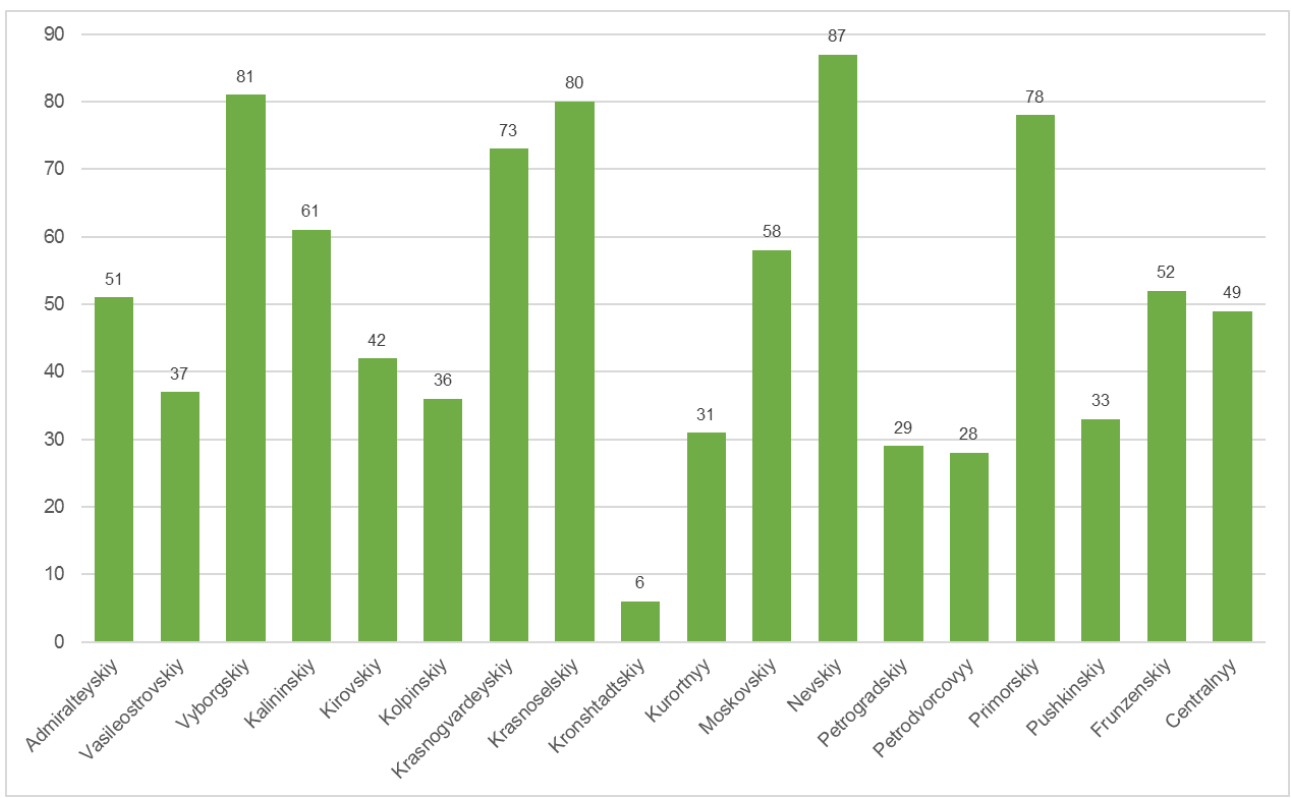

Fig. 1. The number of fires in residential buildings in 2018 .

To determine the radius of service of the fire department there is the calculation which is carried out in accordance with paragraph No. 5.9 of Set of Rules No. 11.13130.2009 for the case of circular spreading of flame over the surface of solids and materials. The maximum permissible distance from the object of the alleged fire to the nearest fire station is determined for one or several purposes of the departure of fire brigade to fire. Since a fire is most likely in a residential building, the calculation is carried out specifically for this situation. Therefore, the calculation verifies the achievement of two goals:

- Goal No. 1 - liquidation of the fire before its area exceeds the area that can be put out by one brigade;

- Goal No.2 - liquidation of fire before the fire resistance of structure reaches critical values.

The initial data for determination of the maximum permissible distance from the object of the alleged fire to the nearest fire station are given in Table 1

Table 1. The initial data.

\begin{tabular}{|c|c|c|c|}
\hline Parameters & $\begin{array}{c}\text { Parameter } \\
\text { designation }\end{array}$ & $\begin{array}{c}\text { Unit of } \\
\text { measurement }\end{array}$ & Value \\
\hline $\begin{array}{c}\text { Line speed of flame spreading in a given } \\
\text { material }\end{array}$ & $\vartheta_{l s}$ & $\mathrm{~m} / \mathrm{min}$ & 0.6 \\
\hline $\begin{array}{c}\text { Time from the moment of fire outbreak until its } \\
\text { detection }\end{array}$ & $\tau_{d t}$ & $\min$ & 1 \\
\hline $\begin{array}{c}\text { Time from the moment of fire detection to the } \\
\text { moment of report to the fire department }\end{array}$ & $\tau_{r}$ & $\min$ & 1 \\
\hline Time of brigade's preparation by alarm & $\tau_{p b}$ & $\min$ & 1 \\
\hline $\begin{array}{c}\text { Time from the moment of arrival to the fire } \\
\text { until the first barrel is delivered to the fire site }\end{array}$ & $\tau_{f b}$ & $\min$ & 2.3 \\
\hline Speed of the fire engine to the place of fire & $\vartheta_{g e}$ & $\mathrm{~km} / \mathrm{h}$ & 30 \\
\hline $\begin{array}{c}\text { The required intensity of fire extinguishing } \\
\text { agent }\end{array}$ & $l_{r i}$ & liter $/\left(\mathrm{m}^{2} \times \sec \right)$ & 0.1 \\
\hline The area of the fire & $S_{a f}$ & $\mathrm{~m}^{2}$ & 15 \\
\hline
\end{tabular}




\begin{tabular}{|c|c|c|c|}
\hline $\begin{array}{c}\text { Area of possible fire at the moment of using the } \\
\text { fire extinguishing agent }\end{array}$ & $S_{\text {ap }}$ & $\mathbf{M}^{2}$ & 170 \\
\hline
\end{tabular}

Table 2. The additional initial data.

\begin{tabular}{|c|c|c|c|}
\hline Parameters & $\begin{array}{c}\text { Parameter } \\
\text { designation }\end{array}$ & $\begin{array}{c}\text { Unit of } \\
\text { measurement }\end{array}$ & Value \\
\hline $\begin{array}{c}\text { Actual fire extinguishing agent consumption that } \\
\text { the fire brigade can deliver to the fire }\end{array}$ & $Q_{a c}$ & liter/sec & 17 \\
\hline $\begin{array}{c}\text { Time from the moment of the fire outbreak until the } \\
\text { fire resistance of structure reaches } \\
\text { critical values. }\end{array}$ & $\tau_{g y}$ & $\min$ & 60 \\
\hline $\begin{array}{c}\text { Necessary time for evacuation of people from the } \\
\text { fire area }\end{array}$ & $\tau_{e p}$ & $\min$ \\
\hline
\end{tabular}

Table 3. The results.

\begin{tabular}{|c|c|c|c|}
\hline Parameters & $\begin{array}{c}\text { Parameter } \\
\text { designation }\end{array}$ & $\begin{array}{c}\text { Unit of } \\
\text { measurement }\end{array}$ & Value \\
\hline \multirow{3}{*}{ Characteristic time } & $T_{1}$ & $\mathrm{~min}$ & 5.3 \\
\cline { 2 - 4 } & $T_{2}$ & $\mathrm{~min}$ & 12.263 \\
\cline { 2 - 4 } & $T_{a}$ & $\mathrm{~min}$ & 10.616 \\
\hline \multirow{2}{*}{$\begin{array}{c}\text { The maximum permissible distance on roads of the } \\
\text { city from the object to the fire station, depending } \\
\text { on the purpose of the departure }\end{array}$} & $l_{1}$ & $\mathrm{~km}$ & 3.482 \\
\cline { 2 - 4 } & $l_{2}$ & $\mathrm{~km}$ & 28.392 \\
\cline { 2 - 4 } & $l_{a}$ & $\mathrm{~km}$ & -2.5679 \\
\hline City Square & $S_{\tilde{c}}$ & $\mathrm{~km}^{2}$ & 1439 \\
\hline The tortuosity coefficient of the way & $\mathrm{k}$ & - & 1.41 \\
\hline Fire Station Service Area & $S_{a}$ & $\mathrm{~km}^{2}$ & 28.26 \\
\hline Fire Station Service Radius & $\mathrm{R}$ & $\mathrm{km}$ & $2.5 / 3$ \\
\hline Required number of fire stations & $\mathrm{N}$ & quantity & 51 \\
\hline
\end{tabular}

The speed of fire engine was accepted $30 \mathrm{~km} / \mathrm{h}$ (however, in Set of Rules No. 232.1311500.2015 "Fire protection of enterprises. General requirements" according to paragraph No. 6.2, the average calculation speed for traveling on hard surfaces is $50 \mathrm{~km} / \mathrm{h}$, for gravel $40 \mathrm{~km} / \mathrm{h}$, for unpaved $30 \mathrm{~km} / \mathrm{h}$ ) due to the fact that the technique does not take into account such factors as: complex traffic situation (traffic jams, road repairs), the mentality of owners of civilian cars (often they simply don't pass fire engine, believing that the extra 10-15 seconds will not help extinguish the fire), outdated equipment. The main reason for reducing the speed to this value is the violation of a fire access road in yards (direct access of the engine to the windows of the house where a fire may occur). These typical examples are illustrated in Figures 2 and 3.

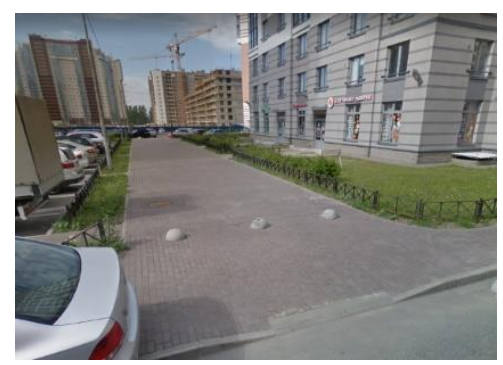

Fig. 2. Example of blocked fire. 


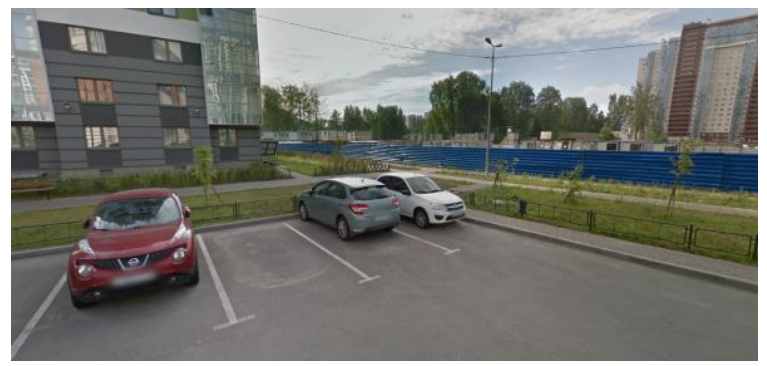

Fig. 3. Example of absence of fire access road.

\section{Results}

As a result of the calculation, it cleared up that the maximum service radius of one fire department is $2.5 \mathrm{~km}$. In accordance with Set of Rules No.42.13330.2011, this distance is 3 $\mathrm{km}$. These radii of $2.5 \mathrm{~km}$ and $3 \mathrm{~km}$ are marked on a map of St. Petersburg, where areas with an insufficient number of fire departments are clearly visible.

Most of them are concentrated in the center of city, and a significant drawback is obvious in areas such as Parnas, Veteranov Prospect, most of the Kurortny district. However, most of St. Petersburg is built up with private houses outside the road ring, or the land simply doesn't suitable for the construction (marshy soil).

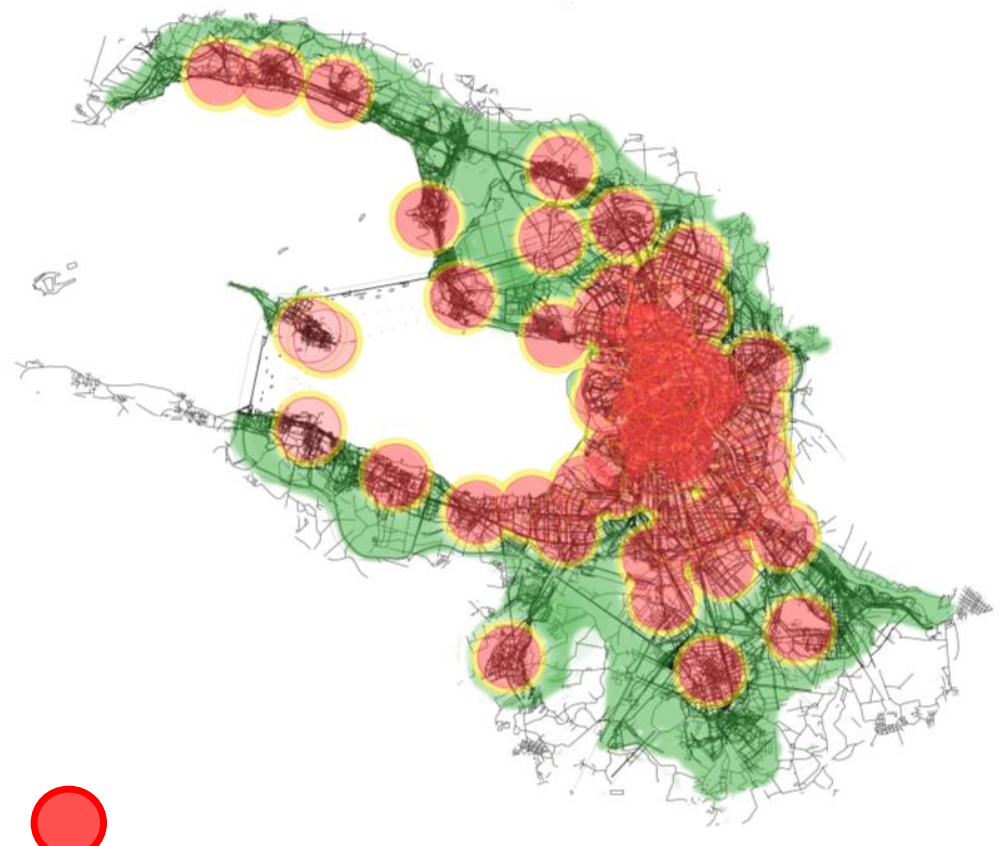

- $2.5 \mathrm{~km}$ radius of service.

- $3 \mathrm{~km}$ radius of service.

Fig. 4. Map of St. Petersburg with the designation of the radius of fire stations' service. 
Mostly these are new developing areas where the number of residential complexes is very big. The drawback of fire departments here can lead to tragic consequences.

However, at the moment the number of fire stations is 62 throughout the city, but the required number is even less -51 .

\section{Discussion}

Krasavin A.V. in its article considers several regulatory documents related to fire safety, specifically the Federal Law "Technical Regulation on Fire Safety Requirements" dated 07.22.2008 No. 123-FL, Set of Rules No. 11.13130.2009 and Set of Rules No. 42.13330.2011. The author denotes that the existing standards have high requirements, the implementation of which in the modern environment, especially in the complex, is impossible. During the calculating one issue, it is necessary to answer it several times in accordance with certain standards. The justification of problem solution because of conflict of norms cannot be single and that leads to complications in the work of designers and experts. The same problems are identified in this article.

\section{Conclusions}

Current regulatory documents governing fire safety require improvement, since the requirements presented by them cannot be fulfilled together. The calculation of the distance from the fire department to the object of the alleged fire (residential building) showed that the required radius of service of one fire station is $2.5 \mathrm{~km}$. As can be seen from the constructed map of St. Petersburg, not all areas of the city are in the safety zone, in other words where fast response of firefighters is provided. Also, it can be noticed that a significant number of fire stations are located in the city center, and their service radii overlap. From the calculation it is clear that the required quantity of fire departments is 51, but there are more of them in reality, which proves the irrationality of their location. Probably, this problem mainly caused because of historical reason, since the city is developing from the center to all directions. Also, probably, this problem deepens by the inaccuracy and uncertainty of fire safety regulations. Therefore, it is necessary to unify all fire standards in order to facilitate the process of calculation and design, and to increase the efficiency of fire departments.

\section{References}

1. M.V. Gravit, D. Serdjuks, et al., Civil Engineering Journal, 1 (85), 92-106 (2019) DOI: 10.18720/MCE.85.8

2. M.V. Gravit, M.D. Terekh, et al., IOP Conference Series: Materials Science and Engineering, 012016 (2018)

3. A. Shukhardin, G. Nefedov, et al., Advances in Intelligent Systems and Computing, 982, 836-844 (2020)

4. M.V. Gravit, N. Klimin, et al., Ministry of Science and Higher Education of the Russian Federation of Peter the Great St.Petersburg Polytechnic University, 012095 (2019)

5. T.V. Nazmeeva, N.I. Vatin, Mag. Civil Eng., 62(2), 92-101 (2016) DOI: 10.5862/MCE.62.9

6. M. Gravit, I. Dmitriev, A. Ishkov, IOP Conf. Ser: Earth Environ. Sci., 90(1), 012226 (2017) DOI: 10.1088/1755-1315/90/1/012226 
7. M. Gravit, O. Zybina, et al., Advances in Intelligent Systems and Computing, 692, 1093-1101 (2018) DOI: 10.1007/978-3-319-70987-1_118

8. M. Gravit, V. Lyulikov, et al., MATEC Web of Conferences, 193, 03026 (2018) DOI: 10.1051/matecconf/201819303026

9. M.V. Gravit, O.V. Nedryshkin, et al., Mag. Civil Eng., 77(1), 38-46 (2018) DOI: 10.18720/MCE.77.4

10. A.J.P.M. Correia, J.P.C. Rodrigues, Fire Saf. J., 50, 1-11 (2012) DOI: 10.1016/j.firesaf.2011.12.010

11. A. Hamins, K. McGrattan, et al., Fire Saf. Sci. (2005) DOI: 10.3801/iafss.fss.8-189

12. M. Heinisuo, T. Jokinen, Mag. Civil Eng., 5(49), 107-120 (2014) DOI: 10.5862/MCE.49.11

13. P. Schaumann, F. Tabeling, W. Weisheim, J. Struct. Fire Eng., 7(2), 158-167 (2016)

14. P. Schaumann, O. Bahr, et al., Tubular Structures XI, 411-416 (2017) DOI: 10.1201/9780203734964-50

15. S.K. Koh, M. Mensinger, P. Meyer, P. Schaumann, 2nd International Fire Safety Symposium, IFireSS 2017, 781 (2017)

16. EN1993-1.2. Design of steel structures. General rules. Structural fire design. European Committee for Standardization, Brussels, Belgium (2004 )

17. N.D. Kankanamge, M. Mahendran, Thin-Walled Struct., 49, 26-44 (2011) 10.1016/j.tws.2010.08. 004 DOI: 10.1016/j.tws.2010.08.004

18. I. Schwarz, M. Slatinka, et al., Appl. Struct. Fire Eng., 129947 (2015) DOI: 10.14311/asfe.2015.021

19. F. Arrais, N. Lopes, P. Vila Real, Appl. Struct. Fire Eng., 129947 (2017) https://doi. org/ DOI: 10.14311/asfe.2015.022 